\title{
Improving the care management of trans patients: Focus groups of nursing students' perceptions
}

\author{
Francisco Montes-Galdeano MSc, RN, Registered Nurse ${ }^{1,2}$ | Pablo Roman MSc, PhD, RN, \\ Vice Dean and Lecturer ${ }^{1,3,4}$ (D) | Carmen Ropero-Padilla MSc, PhD, RN, Lecturer ${ }^{5,6}$ | \\ Agustín Romero-López BA, MA, Lecturer ${ }^{7,8}$ | Cristofer Ruiz-González MSc, RN, Registered \\ Nurse $^{1,2}$ | Miguel Rodriguez-Arrastia MSc, PhD, RN, Lecturer ${ }^{5,6}$
}

${ }^{1}$ Department of Nursing Science, Physiotherapy and Medicine, Faculty of Health Sciences, University of Almeria, Almeria, Spain

${ }^{2}$ Torrecardenas University Hospital, Almeria, Spain

${ }^{3}$ Health Research Centre, University of Almeria, Almeria, Spain

${ }^{4}$ Research Group CTS-451 Health Sciences, University of Almeria, Almeria, Spain

${ }^{5}$ Pre-Department of Nursing, Faculty of Health Sciences, Jaume I University, Castello de la Plana, Spain

${ }^{6}$ Research Group CYS, Faculty of Health Sciences, Jaume I University, Castello de la Plana, Spain

${ }^{7}$ Department of Geography, History and Humanities, Faculty of Humanities, University of Almeria, Almeria, Spain

${ }^{8}$ Research Group HUM-472 Laboratory of Social and Cultural Anthropology, University of Almeria, Almeria, Spain

\section{Correspondence}

Pablo Roman, Department of Nursing Science, Physiotherapy and Medicine, Faculty of Health Sciences, University of Almeria, Ctra. Sacramento s/n, 04120, La Cañada de San Urbano, Almeria, Spain. Email: pablo.roman@ual.es

Carmen Ropero-Padilla, Pre-Department of Nursing, Faculty of Health Sciences, Jaume I University, Castello de la Plana, Av. Sos Baynat, 12071, Castello de la Plana, Spain. Email: ropero@uji.es

\begin{abstract}
Aim: To know the perspectives of nursing students in trans patients' care and their access to health services and how to improve the quality of care in trans patients, related to the barriers identified by nursing students.

Background: Lesbian, gay, bisexual, transgender, queer and plus (LGBTQ+) find barriers related to the health care access, including stigma, discrimination and lack of education. In addition, to the transphobia reported in some health care providers.

Methods: A descriptive qualitative study was performed through 12 focus group interviews in nursing students. Data analysis was based on content analysis.

Results: 124 first-year nursing students participated. The qualitative analysis resulted in three major themes: (a) Exposing an invisible reality, (b) Interprofessional communication: a starting point to arise awareness and (c) Care with pride as a link between individuality and professionalism.

Conclusions: Our findings suggest that both LGBTQ+ content and institutional resources are the cornerstone for nursing students and professionals' practice in order to develop and provide a well-informed and high-quality care delivery to these patients.

Implications for Nursing Management: Policymakers, senior charge nurses and other managers should be aware of the structural-level changes identified and ongoing mentoring needed to guarantee trans patients' privacy and safety.
\end{abstract}

\section{KEYWORDS}

attitudes, LGBTQ persons, nursing students, transgenders

\section{1 | INTRODUCTION}

Transgender or trans* is an umbrella term that includes all the people who do not fit with the prevailing gender binary categorization of male or female. In this vein, the person's gender identity or expression differs from their birth sex (Gridley et al., 2016), which might include non-cisgender, genderqueer, gender variant, gender non-conforming, gender non-binary and agender (Sharek et al., 2020).

Approximately, a total of 25 million of people worldwide identify as trans (Winter et al., 2016). Nevertheless, the current prevalence 
of gender identity is the tip of the iceberg, in which its estimated rate worldwide is ranged only between $0.1 \%$ and $0.6 \%$ (Karalexi et al., 2020; Scheim et al., 2020). Besides that, lesbian, gay, bisexual, transgender, queer and plus (LGBTQ+) find three barriers related to the health care access: stigma, discrimination and lack of education. Likewise, there are other barriers, given that trans-people avoid the use of health services because they perceived a lack of formative and experience about LGBTQ+ care in health care professionals (Paradiso \& Lally, 2018). In that manner, some of them reported negative experiences (Prunas et al., 2016), mostly related to the presumption of risky practices (Kuzma et al., 2019) and the use of heterosexist language (Bonvicini, 2017), invaliding their trans-identity (Stewart \& O'Reilly, 2017). According to these experiences, the documentation and health history do not usually report the felt gender identity (McNeil et al., 2012). This cissexism makes difficult to get access to certain services such as urology or gynaecology (American Psychological Association, 2015).

In relation to the health care staff, the literature has reported mainly the nonexistence or a lack of specific training in the care LGBTQ+ patients (Spidsberg \& Sørlie, 2012). Although several studies have reported the importance of this content to improve therapeutic relationships, however gender diversity competences in curriculums are inadequate, poor or poor formulated, if present (Paradiso \& Lally, 2018). Nursing staff is considered by trans-people as open, receptive, respectful and supportive (Stewart \& O'Reilly, 2017), but it is often that some nursing staff have to confront others co-workers in defence of trans-people, trying to improve patient care and reduce stigma (Schuster, 2012). In general, men health care providers usually show significantly higher levels of transphobia than women. Yet, the perceived discrimination is higher in transwomen compared to transmen, as well as the religious fundamentalism is associated with transphobia (Fisher et al., 2017).

Taking into account the increase in trans-reality and their attention in different nursing units, as an improvement in the gender diversity study plan, the aim of this study was to know the perspectives of nursing students in trans patients' care and their access to health services and how to improve the quality of care in trans patients, related to the barriers identified by nursing students.

\section{2 | MATERIALS AND METHODS}

\section{1 | Design and setting}

In March 2019, a descriptive qualitative study was performed through focus group interviews. The study was conducted in the Faculty of Health Sciences (University of Almería, Spain) between students enrolled in Gender, Multicultural and Health (6 ECTS), a first-year subject in which students received theoretical and practical lessons about the LGBTQ+ patients care and specific attitudes to care this population, between other competences. Data collection was conducted after performing a clinical simulation scenario, in which aim was to understand the needs of trans patients by interacting with a real patient. In a first phase, students had to perform a nursing assessment to a trans standardized patient who was admitted for a bilateral mastectomy, and the personal information on the clinical history was wrongly misplaced in relation to his gender. The patient had to show an attitude of weariness and anger if students were mistakenly referring to him, either by name or by gender. After the assessment, students had to do the handover with a fellow nurse who made discriminatory and transphobic comments.

\section{2 | Participants}

Participants were selected by a convenience sampling. The inclusion criteria were those students who: (a) assisted at least $80 \%$ of lessons, (b) participated in the clinical simulation and (c) were willing to provide written informed consent.

\section{3 | Data collection}

A total of 12 focus groups (FG) interviews were carried out, where 9-11 students participated in each one. Previously to this, informed consent was obtained. Each focus group was led by two researchers, one specialist in lead group dynamics and the other who assisted him and took the field notes. A semi-structured interview guide was developed (Table 1). Each focus group lasted between 40 and 60 min and was recorded. It finalized when no new themes emerged.

\subsection{Data analysis}

Data analysis was based on content analysis, supported by the software program ATLAS.ti 8.4. First, a transcription of the focus groups was done, followed by an in-depth analysis using the Colaizzi's six steps (Wirihana et al., 2018): (a) review and familiarize oneself with the data; (b) identify significant statements; (c) formulate a meaning of the statements within the context; (d) group and organise the identified meanings into clusters of themes. This step will reveal common patterns or trends in the data; (e) a full and inclusive description of the feelings and ideas of participants about each theme and each participant; and (f) the researcher elaborates a fundamental structure or theory.

\section{5 | Validity, reliability and rigour}

Recommendations of the Consolidated criteria for reporting qualitative research (COREQ) were followed. The validity and triangulation were checked by performing an independent content analysis (MRA and (RP), and in case of doubt, a third researcher (PR) was also consulted. Additionally, in the data collection process, a moderator and observer were present with the aim of monitoring the non-verbal communication of the participants. 
TAB LE 1 Script for focus groups

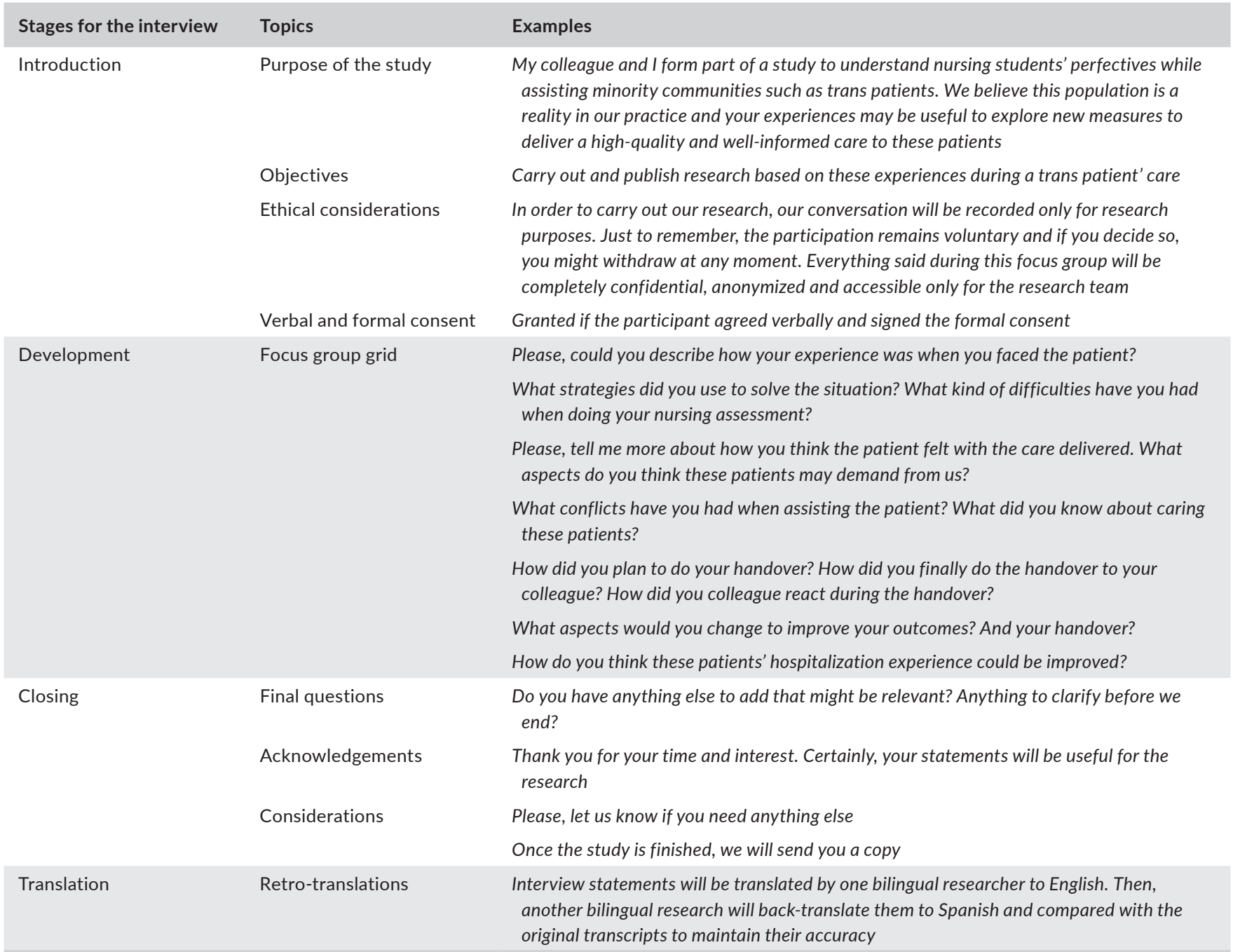

\subsection{Ethical considerations}

The study was approved by the Ethics Committee of the University of Almeria (Spain), and all ethical aspects of the Declaration of Helsinki were taken into account. Additionally, the participants were informed that their experiences, perceptions and opinions would have any influence in their scores.

\section{RESULTS}

\section{1 | Participant characteristics}

We conducted a total of 12 FGs where 124 first-year nursing students participated from a total of 135 students ( $n=91.85 \%)$. The students' average age was 19.87 years old $(S D=4.78)$, with a range from 18 to 54 years. Overall, $77.4 \%$ of participants $(n=96)$ identified as female and $22.6 \%$ as male $(n=28)$, whereas $88.7 \%(n=110)$ self-reported as heterosexual and $11.4 \%(n=14)$ as LGBTQ+. The qualitative analysis resulted in 3 major themes that are summarized in Table 2.

\subsection{Theme 1: Exposing an invisible reality}

This first theme consisted of 2 subthemes and illuminated participants' first experience assisting a trans patient while doing their nursing assessment for his transitioning process. Particularly, our data revealed what communication skills our participants perceived as having, as well as both the level of self-awareness in trans patients care and a need for further knowledge.

\subsection{1 | Subtheme 1.1: The communication as a core stone in nursing care}

For most of the participants, the nursing assessment of a real trans patient was a fascinating and trendy experience, which helped them 
TABLE 2 Themes, subthemes, number of extracts and representative quotes

$\begin{array}{ll}\text { Main theme } & \text { Subthemes } \\ \begin{array}{l}\text { Exposing an invisible } \\ \text { reality }\end{array} & \begin{array}{c}\text { The communication as a core stone in } \\ \text { nursing care }\end{array}\end{array}$

Integrating LGBTQ + content in nursing curricula

\begin{abstract}
Interprofessional communication: a starting point to arise
\end{abstract} awareness

Care with pride as a link between individuality and professionalism
Shortcomings during the handover

When preparedness becomes essential
Learning in LGBTQ+ terminology and its implications
Confronting diversity normalization

The need for a change in the management of transgender patients

\section{Representative quotes}

I was shocked with the experience. I was freeze because it was our first case with a real person, and I didn't expect a case of this kind. I've been surprised, but I loved the exercise. G10-P10

I knew that the case was about a trans, but it didn't make any difference in how I treated him. I've been paralyzed because I didn't know what to do nor what to ask. I felt very nervous and uncomfortable because of the prolonged silences and you could notice that the patient wasn't comfortable either. I didn't know how to manage the situation. G4-P3

I was a bit nervous and lost because I didn't know what question I should ask him. I didn't know how to act in that situation as I didn't know what to ask, but I could ask him some things step by step. G5-P4

I think it's been productive and useful, but that's made us realise that we still have many things to learn and these contests are barely included in our curricula. To be honest, when it came to the case, I didn't know much about it, neither how to care a trans patient nor about the care that they need specifically. G3-P3

I did know barely nothing until today. We read something about nursing assessment, but it's been a new experience when carrying it out about a real patient. I also knew nothing about the transition process, for example. G9-P2

I knew nothing about how to assist a real patient and less with this specific problematic until the activity itself. It's been very helpful, maybe more activities like this could be done to build-up our knowledge. G6-P2

For the handover, I thought about explaining how the patient was for my colleague to be aware of the situation, especially all the info regarding his transition process. This part was the key to avoid similar mistakes that we made harmlessly. G8-P1

I knew something about how to carry the interview, so I could give a lot of information to my colleague during the handover, but nothing about how to attend this kind of patient from a nursing point of view and less about what he was going through. G7-P2

I think he's been a bit discriminatory. When I told him that the patient's name was Antonio [a man], he told me "Is he a man? Because if he is a man it's not possible to do a mastectomy if it's not a tumour o something like that." G1-P6

I think that he might have been offended at some point because I assigned a female pronoun to him and he had to correct me. I apologised, but unfortunately the damage was done. G12-P9

I wouldn't consider for him to be alone in a room as he might feel banned or something. I would suggest to share the room with a woman as they are more respectful and tolerant in these situations. G5-P7

It's been a shocking and interesting situation. I think we were able to learn a lot. On the other hand, I also felt insecure about how to deal with this kind of patients because it's been a totally new experience. In spite of that, it's something that I'm curious about and I hope I can continue to get more training about it, especially to be able to deliver a good care and research about what we can do to change our working settings. G8-P6

We're familiarised with it [transgenderism] because it's become more and more common, and it's strange who hasn't got a friend who is gay or trans ... Imagine professionals from other generations ... That has to be shocking and they're more reluctant to deal with it. Hospitals should form a specific unit or something with professionals with values and attitudes for the specific and sensitive care of these patients. G4-P7

These patients more than others need to create a nurse-patient bond. Then, they should be guarantee to have a professional as a referee who would be their contact in the system, as a guide ... Otherwise, the system itself will make the patient leave. G5-P6 
to gain a better understanding of this kind of patients care since they had to deal with an unknown situation until then:

It's been something completely new. I have blanked out because this was the first time that we make an assessment to this kind of patient and I didn't where to start with. I have felt very helpless because I didn't know how to act as I didn't have knowledge about caring trans patients. G3-P5

In this matter, one common aspect stated among participants was their lack of experience when communicating with patients in general, but more specifically with trans patients in order to assess their needs during their nursing assessment:

I didn't know how to act because of my lack of experience doing clinical cases. At that moment, I was a bundle of nerves because I didn't know what to ask him and how to carry out the nursing assessment properly. After that, I felt awful due to the bad management of the situation and the giggling that might have bothered him. G4-P1

It's been a shocking experience; I didn't know what to say. I felt a bit awkward at some moments of silence as I didn't know which questions to ask. G8-P1

\subsection{2 | Subtheme 1.2: Integrating LGBTQ+ content in nursing curricula}

On the other hand, most participants also stated that the need of including LGBTQ+ contents into their curricula is essential from their first year of nursing education. At the moment of their experience, they perceived knowledge gaps both personal and professional in caring trans patients and even felt bad in their lack of nursing skills when performing their nursing assessment:

The interview has been a challenge because I didn't know so well how focus the questions, to be honest. At the beginning, I addressed him as Luz [a woman], until he told me how he wanted to be called. I missed a few words addressing him in feminine. That is when I realised the gap in our training about this kind of patient. G3-P4

Likewise, some participants emphasized the effectiveness and helpfulness of these practice-based learning content in their formation as nurses as it helped them to be self-aware when caring trans patients and be able to provide a well-informed care to LGBTQ+ individuals:
I think this kind of practice-based learning is very useful, especially for situations that are likely to make us uncomfortable if we haven't done it before. So, we have been able to learn important things like the problems these patients face during their transition process and the care they may need. G12-P14

\section{3 | Theme 2: Interprofessional communication: a starting point to arise awareness}

This second theme explores the attitudes and perceptions of participants from their experience during a nursing handover with a fellow nurse. More interestingly, it describes how participants perceived others' attitudes towards trans patients and their own reactions.

\subsection{1 | Subtheme 2.1: When preparedness becomes essential}

Most participants understood that their preparedness before the handover was essential in order to provide as much relevant information as possible for their fellow nurse to care the patient appropriately:

I thought to prepare the handover with naturalness and giving as much information as possible about the patient, having in mind everything that the patient told us during the interview. It is important for our colleague to have as much information as possible to avoid a slip-up and be able to offer a good care delivery. G9-P5

In this vein, our participants emphasized the importance of taking the demands of these patients into account, especially when doing their handover at the end of their shift to prevent misunderstandings as happened to them. As they remind, some of them focused their intervention into his gender identity mismatch rather than his health condition, which clearly caused discomfort to their patient when using a wrong name or pronoun:

I beard in mind to tell my colleague everything I registered and what my experience was. During the interview, I missed a few female pronouns even when he told me that wanted to be called as Antonio [a man]. In the end, I was more concerned about his name rather than the real problem he had. G3-P4

I wanted my colleague to be aware that the patient's name was Antonio [a man] and not Luz [a woman] as shown wrongly in his history records, which I wasn't aware from when I came into the patient's room. Despite being corrected by the patient, I had a lot of 
troubles changing the correct pronoun, which I was approaching him with. I think he become offended. G5-P6

\subsection{2 | Subtheme 2.2: Shortcomings during the handover}

Nevertheless, some participants described how their lack of experience and knowledge, both assessing the patient and doing their handover, might have not been enough. Some pointed out they have tried to find some information regarding trans patients, but most of them lacked knowledge of trans patients' transitioning process and other related treatments such as hormones or some type of surgery:

To be honest, I didn't have a clue to carry questions in the nursing assessment. After that and during the handover, I realised that there were important aspects that I didn't know and they were essentials, like being able to explain that Antonio [a man] was transitioning to my colleague. G11-P8

Moreover, almost all participants identify their colleague's discrimination attitudes during their handover. Participants described how their colleague used his position to deprecate their patients for his condition and other gender stereotypes. Despite this, almost none of the participants corrected or confronted their fellow nurse's attitudes:

My colleague's reaction during the handover created an awkward situation because he called him "tranny," in a disparagingly way. He commented if the patient wanted her breast to be removed "for pleasure or not." I was freeze and I didn't know how to react when it was clearly discriminatory. G7-P6

My colleague asked if the patient "had a tumour," assuming that a surgery only can be performed for a bad thing and not for psychological well-being. Moreover, he referred to the patient as "tranny." It was a nasty situation and I felt powerless. I didn't know how to react. G8-P4

\section{4 | Theme 3: Care with pride as a link between individuality and professionalism}

This theme encompasses participants' understating of transgender issues with health care providers and changes needed as result of their introspection and self-reflection to provide an equitable care. These include the importance of knowledge in terminology, recalibrating gender categories and promoting inclusive and transspecific informed care throughout culturally sensitive health professionals.

\subsection{1 | Subtheme 3.1: Learning in LGBTQ+ terminology and its implications}

As mentioned, there is a paucity among participants' understanding of LGBTQ+ terminology, ignoring most of the time the patient's gender identity and taking into account only his gender expression. Participants expressed a confusion about which pronoun to use when caring their trans patient, which was sometimes extended to what room should be assigned:

It has been a problem for me when making a proper use of pronouns, changing my mind-chip to speak in masculine, for example. I have made a few mistakes, but they were not intended. Even so, the fact that I confused him with a woman made me feel a bit awkward as I didn't know how to fix the situation. G1-P9

Some participants presented separate rooms as a possible solution for trans patients in order to keep everyone's comfort or avoid further problems, while others saw this separation as a kind of isolation:

I would avoid sharing his room with an elderly person or anyone who doesn't share his opinion and beliefs. So, we could avoid problems from both sides as he doesn't deserve have a hard time because of others' beliefs. Nothing would happen if the patient stayed alone in his room either way. G12-P10

I wouldn't treat him differently from other patients, so he could share a room. Identifying himself as a man, he could share a room with another man, although he could be provided with a single room. Nevertheless, I would try to avoid this last option because I think we shouldn't isolate him just because he "might" cause some problems or make feel uncomfortable to others. G2-P3

The complexity of transgender patients coupled with this participants' lack of knowledge, which is also identified by them as a potential personal and professional bias that might have an influence in their care delivery:

The truth is that I couldn't say with whom he could share the room, for example, but I would try it with someone in his same situation. All of this is quite complex and I think I lack a lot of knowledge on the subject. I may not be totally objective in assessing the patient. G2-P8 


\subsection{2 | Subtheme 3.2: Confronting diversity normalization}

As one of the best approaches, participants' responses reinforce the need to include gender diversity in order to change the nursing practice. They recognized their interventions lacked of a framework that allowed them to provide an individualized and comprehensive care independently of their condition:

I didn't have much knowledge, even less about how to care from a nursing point of view and nothing about the process he was going through. It was quite challenging to think he had a different identity that he already had, mostly when talking to him. Nonetheless, all of this makes me want to train more and be able to offer an equitable and quality care to LGBTQ+ individuals and others. G11-P2

Many of them also identified the need of an important structural-level change to provide privacy and any other options for those who might feel uncomfortable with the current gendered spaces available:

I didn't consider myself to be able to care patients with these characteristics until today class. Nevertheless, I don't think I was prepared enough to deal with this kind of patient, but either to have resources like neutral spaces at hospitals to deliver a good quality of care. Many things need to be changed at all levels. G1-P1

\subsection{3 | Subtheme 3.3: The need for a change in the management of trans patients}

In this matter and in order to guarantee a safe high-quality care to these patients, participants suggested the need to include professional management into the formula. As they identified, senior charge nurses and other health administrators play an essential role to monitor and support their professionals' knowledge and attitudes towards these communities:

They're patients like any other with cancer or appendicitis ... They have enough issues as to add emotional problems because of us. Administrators need to identify professionals and train them to make these kinds of patients feel like one patient more and not some weirdo. We need to evolve. G6-P8

Yet, most participants believed these managers and administrators are in a position to help overcome inequalities in these patients' access to health care system and support them throughout their transitioning process. This help would work both through structural-level changes and professionals' continuous professional development:
Health administrations are limited to a basic attention process to trans patient, if they have such thing, but the problem isn't the surgery for a sex change, it's all what there is before and after. Many patients dilate or ignore their own health issues because of shame or fear. That's unacceptable. Our managers should do something! G2-P10

\section{4 | DISCUSSION}

The aim of this study was to know the perspectives of nursing students in trans patients' care and their access to health services and how to improve the quality of care in trans patients, related to the barriers identified by nursing students. Once our results were analysed, almost all participants reported that their self-awareness about LGBTQ+ individuals' health care needs was increased as a result of the practice-based learning intervention and the importance of their approaches to achieve a positive impact on transgender patients' predisposition to seek help in nurses. These findings are in line with Muckler et al. (2019) and García-Acosta and collaborators' results (2019), who introduced these practice-based learning scenarios to practice therapeutic communication towards trans patients in nurses and final-year nursing students, increasing their confidence and comfort during their care delivery to these patients.

Moreover, these interventions might help nursing students to train transgender-specific attitudes, in order to develop a professional and organisational culture towards these patients (Brown et al., 2018; Stewart \& O'Reilly, 2017). Although most participants had positive and respectful attitudes towards LGBTQ+ individuals, negative attitudes of the nurse during the handover were not criticized by the majority of them. One possible explanation for these findings may be reflective of the own participants' societal attitudes, which includes homophobia, sexism, racism and genderism, and where this kind of learning becomes more relevant (Hojat, 2016; Lim $\&$ Hsu, 2016). Likewise, these positive and negative attitudes might be defined by two independent attitude components, but both modifiable in different grades. On one side, an implicit attitude resulted from an encounter, which would trigger an automatic reaction. And from another, an explicit attitude resulted from a conscious evaluation and, therefore, a learned attitude (Echebarria-Echabe, 2013).

In line with other studies, our participants emphasized the need of promoting a positive health care team communication and respectfully towards patients above all without prejudices and bias in order to build a mutual patient-nurse relationship (Bonvicini, 2017; Haghiri-Vijeh et al., 2020). However, many of them pointed out a lack of communication skills with LGBTQ+ individuals as they stumbled on the correct use of pronouns and felt uncomfortable asking questions in their nursing assessment. For these reasons, LGBTQ+ content on communication in nursing curricula is more essential than ever (Gridley et al., 2016).

Nevertheless, it was found in our findings that participants stated a shortcoming on LGBTQ+ topics in their education. In this 
sense, a scarce of curricula content addressing these issues might have caused a lack skills needed to provide an equitable informed care and, respectively, communication (Muckler et al., 2019). This would be similar to other studies where some barriers were found to implement this kind of topic-specific competencies. Overall, the lack of institutional support and limited curricular time emerged as main barriers, but also the discrete one-time intervention that many times is used for this kind of content, which pedagogical efficacy would be clearly undermined (Paradiso \& Lally, 2018).

This scant LGBTQ+ content in nursing curricula may explain the paucity of students' understanding of gender-related terminology. Because of this, participants faced the challenge to differentiate appropriately between terms such as gender identity or sexual expression during their nursing assessment, which was perceived as a barrier for their care by the students (Maruca et al., 2018). Concordantly, the existing literature suggests that knowledge of LGBTQ+ terminology is crucial to understand and provide a culturally competent care to trans patients, as well as identifying professional and personal bias (Abeln \& Love, 2019). Both educators and senior charge nurses in different organisations have an important role to support and prepare their future and present nurses to create an environment of transinclusivity at work (Carabez et al., 2015; Kcomt et al., 2020).

As recommended by our participants, not only does addressing trans patients' issues begin by educating nurses, but also calling for structural-level changes in order to mitigate heteronormality and cisgenderism. These structural changes include initiatives within health care contexts, such as adopting gender-inclusive record-keeping systems, policies and procedures. For example, decisions on the gendered space for patients often based on staff discretion are frequently taken inappropriately for trans patients (Willging et al., 2019). In this sense, these structural-level changes could advocate for neutral or safe spaces, which guarantee anyone's privacy and options against the current highly gendered spaces (Kellett \& Fitton, 2017; Thornton, 2018). Furthermore, those who do not cluster themselves into a binary model might find these inclusive spaces as a safe place, and therefore, these might serve as a mode of awareness for those nursing students who do their clinical rotations in those institutions. This kind of advocacy model in practicum settings may play an important role to empower nursing's inclusive attitudes and responsibility in their own practice (Kcomt et al., 2020; Lim et al., 2015). Having said that, educators, administrators and other health care managers arise as one of the cornerstones in trans patients' care delivery. They are a key element to support and guide nursing professionals and students in their practice and professional development, which includes LGBTQ+ individuals' needs. In the end, these patients usually attend health services with fear and shame, and there is where the importance of having well-educated professionals and a good management lies (Korpaisarn \& Safer, 2018; Lazarus et al., 2020).

However, there are various limitations into this study to be considered when interpreting our results. First, there is a limited research to our knowledge investigating first-year nursing students experiences assisting trans patients, which has limited our discussion. And second, only first-year nursing students participated in our study. It would be interesting to explore educators' experiences and perceptions towards barriers found integrating LGBTQ+ content in nursing curricula what mechanisms they use to equip nursing students to provide a well-informed and culturally competent care to these patients. Rather than concluding this issue, this study offers an opportunity to address trans patients' perspectives more in detail to gain a deeper understanding of their complex needs or to determine how even these health care needs are perceived in LGBTQ+ older patients.

\section{CONCLUSIONS}

The integration of LGBTQ+ content into nursing curricula could be a useful and supportive initiative from its first year. Likewise, it would be helpful in their clinical practice as part of continuous professional development, notably when practice-based learning scenarios are used. These findings highlight that this content is a key component to develop students and professionals' selfawareness, confidence, nursing skills and sensitivity towards trans patients and other LGBTQ+ individuals in order to provide a competent and well-informed care. Similarly, health care organisations required structural-level changes such as unisex bathrooms or a transgender alternative for male/female checkboxes on standards forms among other measures are needed to facilitate safe or neutral spaces. As suggested in our results, these spaces would guarantee both trans patients' privacy and safety, and a model for nursing students and professionals' inclusive attitudes in their daily practice.

\section{1 | Implications for nursing management}

Since nursing is usually the first point for health care, its role becomes crucial in LGBTQ+ individuals and other minorities' experiences within the health system (McNiel \& Elertson, 2018). In this scenario, both educators, senior charge nurses and other health service managers need to support this leadership role in these patients' care (Carabez et al., 2016). Besides structural-level changes, nurse managers should consider ongoing mentoring for experienced nurses who might have limited information about these populations' health needs in order to be equipped enough to provide a highquality and culturally competent care (Abeln \& Love, 2019; Carabez et al., 2015).

\section{CONFLICT OF INTEREST}

The authors have no conflict of interest to report.

\section{ETHICAL APPROVAL}

The study was approved by the Ethics Committee of the University of Almeria (UALBIO2019/023). 


\section{ORCID}

Pablo Roman (iD https://orcid.org/0000-0002-5966-0498

Miguel Rodriguez-Arrastia iD https://orcid.

org/0000-0001-9430-4272

\section{REFERENCES}

Abeln, B., \& Love, R. (2019). Bridging the gap of mental health inequalities in the transgender population: The role of nursing education. Issues in Mental Health Nursing, 40(6), 482-485. https://doi. org/10.1080/01612840.2019.1565876

American Psychological Association. (2015). Guidelines for psychological practice with transgender and gender nonconforming people. American Psychologist, 70(9), 832-864. https://doi.org/10.1037/a0039906

Bonvicini, K. A. (2017). LGBT healthcare disparities: What progress have we made? Patient Education and Counseling, 100(12), 2357-2361. https://doi.org/10.1016/j.pec.2017.06.003

Brown, S., Kucharska, J., \& Marczak, M. (2018). Mental health practitioners' attitudes towards transgender people: A systematic review of the literature. International Journal of Transgenderism, 19(1), 4-24. https://doi.org/10.1080/15532739.2017.1374227

Carabez, R. M., Eliason, M. J., \& Martinson, M. (2016). Nurses' knowledge about transgender patient care. Advances in Nursing Science, 39(3), 257-271. https://doi.org/10.1097/ANS.0000000000000128

Carabez, R., Pellegrini, M., Mankovitz, A., Eliason, M., \& Scott, M. (2015). Does your organization use gender inclusive forms? Nurses' confusion about trans* terminology. Journal of Clinical Nursing, 24(21-22), 3306-3317. https://doi.org/10.1111/jocn.12942

Echebarria-Echabe, A. (2013). Relationship between implicit and explicit measures of attitudes: The impact of application conditions. Europe's Journal of Psychology, 9(2), 231-245. https://doi.org/10.5964/ejop. v9i2.544

Fisher, A. D., Castellini, G., Ristori, J., Casale, H., Giovanardi, G., Carone, N., Fanni, E., Mosconi, M., Ciocca, G., Jannini, E. A., Ricca, V., Lingiardi, V., \& Maggi, M. (2017). Who has the worst attitudes toward sexual minorities? Comparison of transphobia and homophobia levels in gender dysphoric individuals, the general population and health care providers. Journal of Endocrinological Investigation, 40(3), 263-273. https://doi.org/10.1007/s40618-016-0552-3

García-Acosta, J. M., Castro-Peraza, M. E., Arias Rodriguez, Á., PerezCánovas, M. L., Sosa-Alvarez, M. I., Llabrés-Solé, R., PerdomoHernández, A. M., \& Lorenzo-Rocha, N. D. (2019). Impact of a formative program on transgender healthcare for nursing students and health professionals. Quasi-experimental intervention study. International Journal of Environmental Research and Public Health, 16(17), 1-14. https://doi.org/10.3390/ijerph16173205

Gridley, S. J., Crouch, J. M., Evans, Y., Eng, W., Antoon, E., Lyapustina, M., Schimmel-Bristow, A., Woodward, J., Dundon, K., Schaff, R. N., McCarty, C., Ahrens, K., \& Breland, D. J. (2016). Youth and caregiver perspectives on barriers to gender-affirming health care for transgender youth. Journal of Adolescent Health, 59(3), 254-261. https:// doi.org/10.1016/j.jadohealth.2016.03.017

Haghiri-Vijeh, R., McCulloch, T., Atack, L., \& Bedard, G. (2020). The impact of positive space training on students' communication with LGBTTQ+ communities. Nursing Education Perspectives, 41(2), 115116. https://doi.org/10.1097/01.NEP.0000000000000474

Hojat, M. (2016). Empathy in health professions education and patient care. Empathy in Health Professions Education and Patient Care. https://doi.org/10.1007/978-3-319-27625-0

Karalexi, M. A., Georgakis, M. K., Dimitriou, N. G., Vichos, T., Katsimpris, A., Petridou, E. T., \& Papadopoulos, F. C. (2020). Gender-affirming hormone treatment and cognitive function in transgender young adults: A systematic review and meta-analysis. Psychoneuroendocrinology, 119, 104721. https://doi.org/10.1016/j.psyneuen.2020.104721
Kcomt, L., Gorey, K. M., Barrett, B. J., \& McCabe, S. E. (2020). Healthcare avoidance due to anticipated discrimination among transgender people: A call to create trans-affirmative environments. Ssm-population Health, 11. https://doi.org/10.1016/j.ssmph.2020.100608

Kellett, P., \& Fitton, C. (2017). Supporting transvisibility and gender diversity in nursing practice and education: Embracing cultural safety. Nursing Inquiry, 24(1). https://doi.org/10.1111/nin.12146

Korpaisarn, S., \& Safer, J. D. (2018). Gaps in transgender medical education among healthcare providers: A major barrier to care for transgender persons. Reviews in Endocrine and Metabolic Disorders, 19, 271-275. https://doi.org/10.1007/s11154-018-9452-5

Kuzma, E. K., Graziano, C., Shea, E., Schaller, F. V., Pardee, M., \& Darlingfisher, C. S. (2019). Education improving lesbian, gay, bisexual, transgender, and queer/questioning health: using a standardized patient experience to educate advanced practice nursing students. Journal of the American Association of Nurse Practitioners, 31(12), 714-722.

Lazarus, J. V., Baker, L., Cascio, M., Onyango, D., Schatz, E., Smith, A. C., \& Spinnewijn, F. (2020). Novel health systems service design checklist to improve healthcare access for marginalised, underserved communities in Europe. British Medical Journal Open, 10(4). https://doi. org/10.1136/bmjopen-2019-035621

Lim, F. A., \& Hsu, R. (2016). Nursing students' attitudes toward lesbian, gay, bisexual, and transgender persons: An integrative review. Nursing Education Perspectives, 37(3), 144-152. https://doi.org/10.1097/01. NEP.0000000000000004

Lim, F., Johnson, M., \& Eliason, M. (2015). A national survey of faculty knowledge, experience, and readiness for teaching lesbian, gay, bisexual, and transgender health in baccalaureate nursing programs. Nursing Education Perspectives, 36(3), 144-152. https://doi. org/10.5480/14-1355

Maruca, A. T., Diaz, D. A., Stockmann, C., \& Gonzalez, L. (2018). Using simulation with nursing students to promote affirmative practice toward the lesbian, gay, bisexual, and transgender population: A multisite study. Nursing Education Perspectives, 39(4), 225-229. https:// doi.org/10.1097/01.NEP.0000000000000302

McNeil, J., Bailey, L., Ellis, S., Morton, J., \& Regan, M. (2012). Trans mental health and emotional wellbeing study 2012. Scottish Transgender Alliance. http://www.scottishtrans.org/wp-content/uploa ds/2013/03/trans_mh_study.pdf

McNiel, P. L., \& Elertson, K. M. (2018). Advocacy and awareness: Integrating LGBTQ health education into the prelicensure curriculum. Journal of Nursing Education, 57(5), 312-314. https://doi. org/10.3928/01484834-20180420-12

Muckler, V. C., Leonard, R., \& Cicero, E. C. (2019). Transgender simulation scenario pilot project. Clinical Simulation in Nursing, 26, 44-48. https://doi.org/10.1016/j.ecns.2018.10.007

Paradiso, C., \& Lally, R. M. (2018). Nurse practitioner knowledge, attitudes, and beliefs when caring for transgender people. Transgender Health, 3(1), 47-56. https://doi.org/10.1089/trgh.2017.0048

Prunas, A., Bandini, E., Fisher, A. D., Maggi, M., Pace, V., Quagliarella, L., Todarello, O., \& Bini, M. (2016). Experiences of discrimination, harassment, and violence in a sample of Italian transsexuals who have undergone sex-reassignment surgery. Journal of Interpersonal Violence, 33(14), 2225-2240. https://doi.org/10.1177/0886260515 624233

Scheim, A. I., Perez-Brumer, A. G., \& Bauer, G. R. (2020). Genderconcordant identity documents and mental health among transgender adults in the USA: A cross-sectional study. The Lancet Public Health, 5(4), e196-e203. https://doi.org/10.1016/S2468 $-2667(20) 30032-3$

Schuster, M. A. (2012). On being gay in medicine. Academic Pediatrics, 12(2), 75-78. https://doi.org/10.1016/j.acap.2012.01.005

Sharek, D., McCann, E., \& Huntley-Moore, S. (2020). The design and development of an online education program for families of trans young 
people. Journal of LGBT Youth, 1-23. https://doi.org/10.1080/19361 653.2020.1712296

Spidsberg, B. D., \& Sørlie, V. (2012). An expression of love-Midwives' experiences in the encounter with lesbian women and their partners. Journal of Advanced Nursing, 68(4), 796-805. https://doi. org/10.1111/j.1365-2648.2011.05780.x

Stewart, K., \& O'Reilly, P. (2017). Exploring the attitudes, knowledge and beliefs of nurses and midwives of the healthcare needs of the LGBTQ population: An integrative review. Nurse Education Today, 53, 67-77. https://doi.org/10.1016/j.nedt.2017.04.008

Thornton, M. (2018). LGBT older adults and nurse administrators: An opportunity for advocacy. Nursing Administration Quarterly, 42(2), 129-135. https://doi.org/10.1097/NAQ.0000000000000282

Willging, C., Gunderson, L., Shattuck, D., Sturm, R., Lawyer, A., \& Crandall, C. (2019). Structural competency in emergency medicine services for transgender and gender non-conforming patients. Social Science and Medicine, 222, 67-75. https://doi.org/10.1016/j.socsc imed.2018.12.031

Winter, S., Diamond, M., Green, J., Karasic, D., Reed, T., Whittle, S., \& Wylie, K. (2016). Transgender people: Health at the margins of society. The Lancet, 388(10042), 390-400. https://doi.org/10.1016/ S0140-6736(16)00683-8

Wirihana, L., Welch, A., Williamson, M., Christensen, M., Bakon, S., \& Craft, J. (2018). Using Colaizzi's method of data analysis to explore the experiences of nurse academics teaching on satellite campuses. Nurse Researcher, 25(4), 30-34. https://doi.org/10.7748/nr.2018. e1516

How to cite this article: Montes-Galdeano F, Roman P, Ropero-Padilla C, Romero-López A, Ruiz-González C, Rodriguez-Arrastia M. Improving the care management of trans patients: Focus groups of nursing students' perceptions. J. Nurs. Manag. 2020;00:1-10. https://doi.org/10.1111/ jonm.13160 